\title{
The Italian JAG: endoscopy quality measurement spreads?
}

\section{다)(웅}

\author{
Authors \\ Cesare Hassan ${ }^{1}$, Giulio Antonelli ${ }^{1}$, Mario Dinis-Ribeiro ${ }^{2}$ \\ Institutions \\ 1 Endoscopy Unit, Nuovo Regina Margherita Hospital, \\ Rome, Italy \\ 2 CIDES/CINTESIS, Faculty of Medicine, University of \\ Porto, Porto, Portugal \\ Bibliography \\ DOI https://doi.org/10.1055/a-1118-3658 | \\ Endoscopy International Open 2020; 08: E571-E572
}

\author{
(c) Georg Thieme Verlag KG Stuttgart · New York \\ eISSN 2196-9736 \\ Corresponding author \\ Cesare Hassan, ONRM Hospital - Gastro, Via Morosini 30, \\ Rome 00153, Italy \\ Fax: +390658446533 \\ cesareh@hotmail.com
}

We have spent most of the last 10 years in obsessing about how to increase our adenoma detection rate (ADR) as primary surrogate for desired improvement in the quality of endoscopy. Few would doubt that we have succeeded! Scientific societies produced convincing documents defining the ADR and explaining how it should be achieved [1]. The endoscopy community promptly responded, steadily increasing its level of ADR, assuring a higher degree of clinical and professional standard at the same time population programs for colorectal cancer (CRC) screening were implemented in our European countries. Is that all there is?

ADR is somewhat a holistic indicator, closely related to several characteristics of a center, including its technology, the competence of the endoscopist, and eventually the clinical outcome [1]. It is also true that ADR is quite a cost-neutral indicator because assessing it requires only merging the endoscopic and pathology databases. In addition, gastroenterologists are usually in charge of ADR assessment, given their specialty. It is also an easy indicator because a 1- or 2-day retraining course may be enough to improve it.

On the other hand, ADR represents only an approximation for most of the quality assurance $(\mathrm{QA})$ process in gastrointestinal endoscopy. For instance, it does not provide clear and detailed information on the individual steps in the QA chain. Let's assume that an endoscopist has a low ADR. Are we sure it signals suboptimal competence on the part of the endoscopist? What if a split regimen or high-definition scopes were lacking? The opposite is even more alarming. How many endoscopists somewhat compensate for a suboptimal organization by overperforming with their own dedication and skills? We must admit that despite representing a strong process indicator, ADR does not ensure the homogeneity of behavior required for a reliable standard in gastrointestinal endoscopy. Can't we see the forest for the trees?
Let's take a step back and turn our attention from the endoscopist to the center. Pitfalls in the center structure or organization may not have an immediate impact on procedural outcomes, but they may still result in catastrophic consequences. Any breach in the sequence of manual and machine steps involved in scope reprocessing can result in unexpected postendoscopy infections [2]. Less emphasized, but still relevant issues, are the lack of auditing and reporting in our centers, as well as suboptimal choices in our daily routine or inappropriate patient selection. In other words, we should never pretend that quality will come as a consequence of assessing ADR or similar indicators, whereas the opposite is true: Optimal ADR will be a natural consequence of implementing quality in its largest and broadest sense.

The problem is not what to measure but the who should do the measurement. Let's be honest: As endoscopists we have been trained to execute a safe and effective intervention, but not to objectively assess its quality, perform a root analysis of the main pitfalls, and propose best remedies. In addition, we are somewhat subjective in assessing the QA in our own centers due to an inertial in making disruptive decisions to overcome motivational, economic, and financial barriers. Would you ever trust an airline company that bases its own safety only on the skills of its own pilots?

The Italian Society of Digestive Endoscopy (SIED) reported on a global and systematic approach to objectivize quality assessment, based on center accreditation [3]. Instead of using the local endoscopists, SIED selected an autonomous body to measure and certify the level of quality in as many as 40 gastrointestinal endoscopy centers. Such a certifying body was selected outside the medical field as primarily involved in the quality certification of complex non-medical industry processes. Of course, this body appointed expert endoscopists to define the standards and methods to follow and to audit the sequential 
phases involved in the endoscopic activity. This led to development of a rigorous and analytical methodology for accreditation of gastrointestinal centers that is somewhat innovative and disruptive as compared with our usual way of thinking.

Quoting the SIED report, the main objectives of the accreditation were "the documentation system...the coherence of the mission and the vision, the methods used to achieve the goals, the methods for assessing the competence of the doctors, leadership, and management of human resources" [3]. Despite some differences in outcomes, there are several that overlap with the JAG system in the UK [4]. Both systems were initiated by scientific societies, implemented nationwide, and assured a more transparent and objective assessment of professional standards.

Completeness, traceability, and appropriateness of each individual task by medical and non-medical staff have been rated as ineludible standards for QA implementation in gastrointestinal centers. Most centers were shown to fail in one or more of these fundamental tasks [3]. Adoption of simple steps recommended to rectify these deviations will likely improve not only the safety, but also the benefit of gastrointestinal procedures in these centers. Most of the inspected centers also failed to audit the main quality indicators, confirming that the willingness of individual endoscopists who are enlightened cannot replace a more systematic approach to objectively assess quality [3].

It could be argued that there is no direct evidence that an autonomous non-medical certifying body is better than a medical panel in implementing an accreditation process. However, the authors did an interesting analysis by comparing the outcome of a pre-visit self-assessment with that of the in situ visit [3]. The comparison showed the additional benefit of an autonomous body in detecting systematic errors that remained invisible to the medical staff.
Finally, the enthusiastic nationwide participation of gastrointestinal centers to the SIED initiative indicates that formal accreditation represents an unmet expectation of the endoscopy community. The willingness of endoscopists to be assessed means that after the pioneering phase of self-assessment, the community wants to take a step forward and incorporate the QA initiative into a more global, structured, and professional industry-based approach. Now it is up to scientific societies to exploit the available knowledge and expand this accreditation process across the European centers.

\section{Competing interests}

The authors declare that they have no conflict of interest.

References

[1] Kaminski MF, Thomas-Gibson S, Bugajski M et al. Performance measures for lower gastrointestinal endoscopy: a European Society of Gastrointestinal Endoscopy (ESGE) Quality Improvement Initiative. Endoscopy 2017; 49: 378-397

[2] Beilenhoff U, Biering H, Blum R et al. Prevention of multidrug-resistant infections from contaminated duodenoscopes: Position Statement of the European Society of Gastrointestinal Endoscopy (ESGE) and European Society of Gastroenterology Nurses and Associates (ESGENA). Endoscopy 2017; 49: 1098-1106

[3] Spinzi Giancarlo, Milano Angelo, Brosolo Piero et al. The Italian Society for Digestive Endoscopy (SIED) accreditation and quality improving project based on international standards. Endosc Int Open 2020; 8 : E338-E345

[4] Siau K, Anderson JT, Valori R et al. Certification of UK gastrointestinal endoscopists and variations between trainee specialties: results from the JETS e-portfolio. Endosc Int Open 2019; 7: E551-E560 